\title{
Article \\ Optimization of Spheroid Colony Culture and Cryopreservation of Nucleus Pulposus Cells for the Development of Intervertebral Disc Regenerative Therapeutics
}

\author{
Kosuke Sako ${ }^{1}$, Daisuke Sakai ${ }^{1} *{ }^{\mathbb{D}}$, Yoshihiko Nakamura ${ }^{2}$, Erika Matsushita ${ }^{2}$, Jordy Schol ${ }^{2}$, Takayuki Warita ${ }^{2}$, \\ Natsumi Horikita ${ }^{2}$, Masato Sato ${ }^{1} \mathbb{D}$ and Masahiko Watanabe ${ }^{1, * \mathbb{B}}$ \\ 1 Department of Orthopaedic Surgery, Tokai University School of Medicine, 143 Shimokasuya, Isehara, \\ Kanagawa 259-1193, Japan; k.sako0626@tokai.ac.jp (K.S.); sato-m@is.icc.u-tokai.ac.jp (M.S.) \\ 2 Research Center for Regenerative Medicine, Tokai University School of Medicine, 143 Shimokasuya, Isehara, \\ Kanagawa 259-1193, Japan; kahiko@is.icc.u-tokai.ac.jp (Y.N.); silsilsilring@gmail.com (E.M.); \\ bb.jordy@gmail.com (J.S.); takayuki.warita@tunzpharma.co.jp (T.W.); \\ natsumi.horikita@tunzpharma.co.jp (N.H.) \\ * Correspondence: daisakai@is.icc.u-tokai.ac.jp (D.S.); masahiko@is.icc.u-tokai.ac.jp (M.W.)
}

Citation: Sako, K.; Sakai, D.; Nakamura, Y.; Matsushita, E.; Schol, J.; Warita, T.; Horikita, N.; Sato, M.; Watanabe, M. Optimization of Spheroid Colony Culture and Cryopreservation of Nucleus Pulposus Cells for the Development of Intervertebral Disc Regenerative Therapeutics. Appl. Sci. 2021, 11, 3309. https://doi.org/10.3390/ app11083309

Academic Editor: Andrea Ballini

Received: 28 February 2021

Accepted: 1 April 2021

Published: 7 April 2021

Publisher's Note: MDPI stays neutral with regard to jurisdictional claims in published maps and institutional affiliations.

Copyright: (c) 2021 by the authors. Licensee MDPI, Basel, Switzerland. This article is an open access article distributed under the terms and conditions of the Creative Commons Attribution (CC BY) license (https:// creativecommons.org/licenses/by/ $4.0 /)$.

\begin{abstract}
After the discovery of functionally superior Tie2-positive nucleus pulposus (NP) progenitor cells, new methods were needed to enable mass culture and cryopreservation to maintain these cells in an undifferentiated state with high cell yield. We used six types of EZSPHERE ${ }^{\circledR}$ dishes, which support spheroid-forming colony culture, and examined NP cell spheroid-formation ability, number, proliferation, and mRNA expression of ACAN, COL1A2, COL2A1, and ANGPT1. Six different types of cryopreservation solutions were examined for potential use in clinical cryopreservation by comparing the effects of exposure time during cryopreservation on cell viability, Tie2-positivity, and cell proliferation rates. The spheroid formation rate was $45.1 \%$ and the cell proliferation rate was 7.75 times using EZSPHERE ${ }^{\circledR}$ dishes. The mRNA levels for COL2A1 and ANGPT1 were also high. In cryopreservation, CryoStor10 (CS10) produced $\geq 90 \%$ cell viability and a high proliferation rate after thawing. CS10 had a high Tie2-positive rate of $12.6 \%$ after culturing for 5 days after thawing. These results suggest that EZSPHERE enabled colony formation in cell culture without the use of hydrogel products and that CS10 is the best cryopreservation medium for retaining the NP progenitor cell phenotype and viability. Together, these data provide useful information of NP cell-based therapeutics to the clinic.
\end{abstract}

Keywords: intervertebral disc; nucleus pulposus; nucleus pulposus progenitor cells; cryopreservation; Tie2; spheroid colony; EZSPHERE; CryoStor 10

\section{Introduction}

Low back pain is the primary cause of disability worldwide and often leads to poor quality of life for patients [1,2]. Low back pain is thought to relate to intervertebral disc (IVD) degeneration, although the mechanisms have not been clearly identified [3]. The IVD is composed of three distinct tissues: the nucleus pulposus (NP), annulus fibrosus (AF), and cartilage endplate. The NP comprises the gelatinous tissue located in the center of the IVD. The AF comprises layered collagen structures that surround the NP [4]. Previous reports have indicated that IVD homeostasis is determined by the NP [5,6] and that IVD degeneration is thought to be caused by dysregulation of extracellular matrix (ECM) homeostasis within the NP tissue $[7,8]$.

Disc degeneration is associated with a decline in NP cell numbers and potency, and renewal by stem or progenitor sources appears to be limited [9]. Interestingly, in 2012, Sakai et al. discovered a specific NP progenitor cell population species [9]. NP progenitor cells were shown to have the ability for self-renewal and multipotency, including 
adipogenic, osteogenic, and neurogenic differentiation potential [9-12]. NP progenitor cells were reported to differentiate into two types of colony-forming units upon culture in methylcellulose semisolid medium: spheroid colony-forming units (CFU-s) with high ECM production and fibroblastic colony-forming units (CFU-f) with low functionality $[9,13]$. The propensity of NP progenitor cells for CFU-s was linked to the expression of the cell surface marker angiopoietin-1 receptor (Tie2) [9]. Tie2-expressing NP progenitor cells have since been identified in human, canine, murine, and bovine IVD samples [12-14]. Interestingly, the presence of Tie2-expressing cells within the IVD declines sharply with aging [9] and is similarly linked with progression of disc degeneration [9]. Thus, Tie2 progenitor cells provide a promising therapeutic target in the treatment of IVD degeneration.

Cell therapy is a rapidly evolving field and is thought to be safe and effective for the treatment of low back pain associated with degenerating IVDs [15] Cell therapy has been suggested to be effective through repopulation of the IVD cells or reactivation of endemic cells through paracrine signaling, thereby switching the disc environment from catabolic to anabolic [15]. Our group has conducted one of the first IVD cell therapy clinical trials, which involved the transplantation of autologous NP cells that were reactivated using coculture with mesenchymal stem cells (MSCs) [16]. The trial revealed that NP cells could be safely transplanted and that cell transplantation appears to be effective in preventing disc degeneration [16].

Although these results are promising, NP materials are often derived from aged and diseased patients, which can compromise their regenerative potential [17-19]. We believe that the potency of NP cell therapy could be increased by using a cell population with high Tie2-positive rates. However, Tie2-positive cells remain difficult to maintain in culture because they rapidly lose their Tie2 expression and consequently their proliferative capacity and potency [13]. In addition, mass production of these cells is limited by the high viscosity of the methylcellulose medium and unsuitability for industrialization.

A variety of studies have investigated ways to improve the culture conditions $[10,14,20]$ or isolation methods [21] to increase the number of Tie2-expressing cells. For example, Tekari et al. reported beneficial effects of fibroblast growth factor 2 (FGF2) and hypoxic culture conditions [14]. Recent work by Guerrero et al. [10] showed the benefits of threedimensional (3D) pellet culture environments for maintaining the multipotent capacity and retaining Tie2 expression in Tie2-positive NP progenitor cells. These findings provide evidence for the potential of culture augmentation to increase the retention of NP progenitor cells. However, an optimized culture method that would be scalable, marketable, and clinically applicable remains to be determined.

Another consideration that could hinder the translation of Tie2-positive NP progenitor cells to the market is their preservation. Tanaka et al. has shown that cell viability, differentiation ability, and ECM production do not change significantly from before to after NP cell cryopreservation [22]. This finding suggests that activated NP cells could be used in a cryopreserved state whenever needed according to the patient's condition, thus increasing their potential as a commercial, mass-produced, off-the-shelf (OTS) regenerative therapeutic product. In a canine study, an OTS discogenic NP cell product was shown to be as effective in regenerating induced disc degeneration compared with freshly cultured cells [23]. These products are currently undergoing clinical trial evaluations (NCT03347708, NCT03955315).

There is a large difference between the actual clinical application and the results in laboratory-based reports. In addition, the time required before and after freezing is rarely considered [24]. The cytotoxicity of animal serum and dimethyl sulfoxide (DMSO) contained in the cryopreservation solutions may also present safety and regulatory problems during clinical applications $[13,25]$. Furthermore, during the product management and transportation after mass culture, the process from cell isolation to storage becomes more complicated and time consuming.

We wanted to examine the potential for optimization of the practical aspects of NP cell production in terms of cell culture, storage, and logistic handling. Given the needs of 
future commercialization, we aimed to identify optimal cryopreservation solution(s) that could limit the functional deterioration and maintain the high cell viability of Tie2-positive NP cells. We examined the potential for using specialized nonadherent EZSPHERE ${ }^{\circledR}$ dishes, which have been used with induced pluripotent stem cells and cancer cells but not with NP cells. This culture dish supports 3D cell cultures without the need for hydrogel encapsulation to enable mass production of spheroid-forming NP cells.

\section{Materials and Methods}

\subsection{Human NP Cell Isolation}

Human NP tissues were collected from 10 patients undergoing surgery for lumbar disc herniation at Tokai University Hospital and related facilities (Table 1). All patients provided their informed consent for the collection and use of surgical waste for research purposes. All research procedures described in this study were approved by the Institutional Review Board for Clinical Research, Tokai University (application number 16R-051: 15 July 2016).

Table 1. Details of clinical samples. Age, sex, total weight of IVD tissue collected at the time of surgery, and weight of NP tissue after selection are listed for each sample. LDH: lumber disc hernia, IVD: intervertebral disc, NP: nucleus pulposus.

\begin{tabular}{ccccccc}
\hline Code & Age & Sex & Disease & $\begin{array}{c}\text { IVD Tissue } \\
\text { Amount(g) }\end{array}$ & $\begin{array}{c}\text { NP Tissue } \\
\text { Amount(g) }\end{array}$ \\
\hline 1 & T19 & 19 & M & LDH & 8.05 & 7.59 \\
2 & A29 & 29 & F & LDH & 3.76 & 2.57 \\
3 & K30 & 30 & F & LDH & 4.26 & 2.5 \\
4 & E32 & 32 & F & LDH & 4.75 & 4.75 \\
5 & A16 & 16 & F & LDH & 3.58 & 1.9 \\
6 & K21 & 21 & F & LDH & 7.52 & 4.79 \\
7 & A24 & 24 & M & LDH & 8.04 & 4.6 \\
8 & T23 & 23 & M & LDH & 5.06 & 3 \\
9 & T18 & 18 & M & LDH & 3.38 & 3.73 \\
10 & A18 & 18 & M & LDH & 5.88 & \\
\hline
\end{tabular}

NP cells were isolated as described previously [13]. Briefly, the collected NP tissue was washed with excess saline and the tissue wet weight was measured. In a $100 \mathrm{~mm}$ dish, the tissue was cut into $3-5 \mathrm{~mm}$-sized pieces with sterilized scissors and scalpels. The shredded NP tissue was carefully transferred to a $50 \mathrm{~mm}$ conical tube and centrifuged at $1200 \mathrm{rpm}$ for $5 \mathrm{~min}$ at $4{ }^{\circ} \mathrm{C}$. After centrifugation, the supernatant was removed, and the tissue was resuspended in $10 \mathrm{~mL}$ of $10 \%(v / v)$ fetal bovine serum (FBS), minimal essential medium $\alpha$ (MEM $\alpha$, Fujifilm Wako Pure Chemical Corporation, Osaka, Japan), and $10 \mathrm{~mL}$ of TrypLE Express (Thermo Fisher Scientific, Tokyo, Japan). The suspension was incubated with gentle swirling at $37^{\circ} \mathrm{C}$ for $1 \mathrm{~h}$. The tissue dissolution state was confirmed and the sample was centrifuged at $1800 \mathrm{rpm}$ for $5 \mathrm{~min}$. Next, the tissue was resuspended in $15 \mathrm{~mL}$ of $10 \%$ FBS-MEM $\alpha$ and $5 \mathrm{~mL}$ of $0.25 \mathrm{mg} / \mathrm{mL}$ collagenase P (Roche, Basel, Switzerland), and incubated for $2 \mathrm{~h}$ at $37^{\circ} \mathrm{C}$. After digestion, the tissue was again centrifuged and resuspended in $20 \mathrm{~mL}$ of $10 \%$ FBS-MEM $\alpha$, the cell suspension was filtered through a $40 \mu \mathrm{m}$ cell strainer (Corning, Corning, NY, USA), and the cells were subjected to experimental cryopreservation or culture conditions as described below.

\subsection{NP Cell Culture Conditions}

Primary human NP cells $(n=4$, Table 1: T19, A29, K30, E32) were suspended at 10,000 cells $/ \mathrm{mL}$ in $10 \%$ FBS-MEM $\alpha$. Cells were seeded in $2 \mathrm{~mL}$ onto different types of EZSPHERE ${ }^{\circledR}$ plates (spheroid-formation culture vessel: IWAKI, Tokyo, Japan) and cultured at $37{ }^{\circ} \mathrm{C}$ in $5 \% \mathrm{CO}_{2}$ and $5 \% \mathrm{O}_{2}$ for 14 days. EZSPHERE ${ }^{\circledR}$ plates have a uniform well structure on the surface of the dish that allow cells to form different shapes of germ layers or spheroids depending on the size and type of the well (Figure 1). Here we used the following EZSPHERE ${ }^{\circledR}$ dish types: 4000-900 (caliber: $500 \mu \mathrm{m}$, depth: $100 \mu \mathrm{m}$, 
number of wells: 2300); 4000-901 (caliber: $200 \mu \mathrm{m}$, depth: $100 \mu \mathrm{m}$, number of wells: 9200); 4000-902 (diameter: $500 \mu \mathrm{m}$, depth: $200 \mu \mathrm{m}$, number of wells: 2300); 4000-903 (diameter: $800 \mu \mathrm{m}$, depth: $400 \mu \mathrm{m}$, number of wells: 600), and 4000-904 (diameter: $800 \mu \mathrm{m}$, depth: $300 \mu \mathrm{m}$ ), number of wells: 200); type 4000-905 (caliber: $1400 \mu \mathrm{m}$, depth: $600 \mu \mathrm{m}$, number of wells: 2300). After 2 weeks of culture, the established colonies were collected carefully by pipetting. For analysis of marker expression, standard monolayer culture was performed by seeding NP cells at a density of $4.5 \times 10^{5}$ cells $/ \mathrm{cm}^{2}$ into $100 \mathrm{~mm}$ plates and culturing them under identical conditions for 7 days. These cells were used as the control.
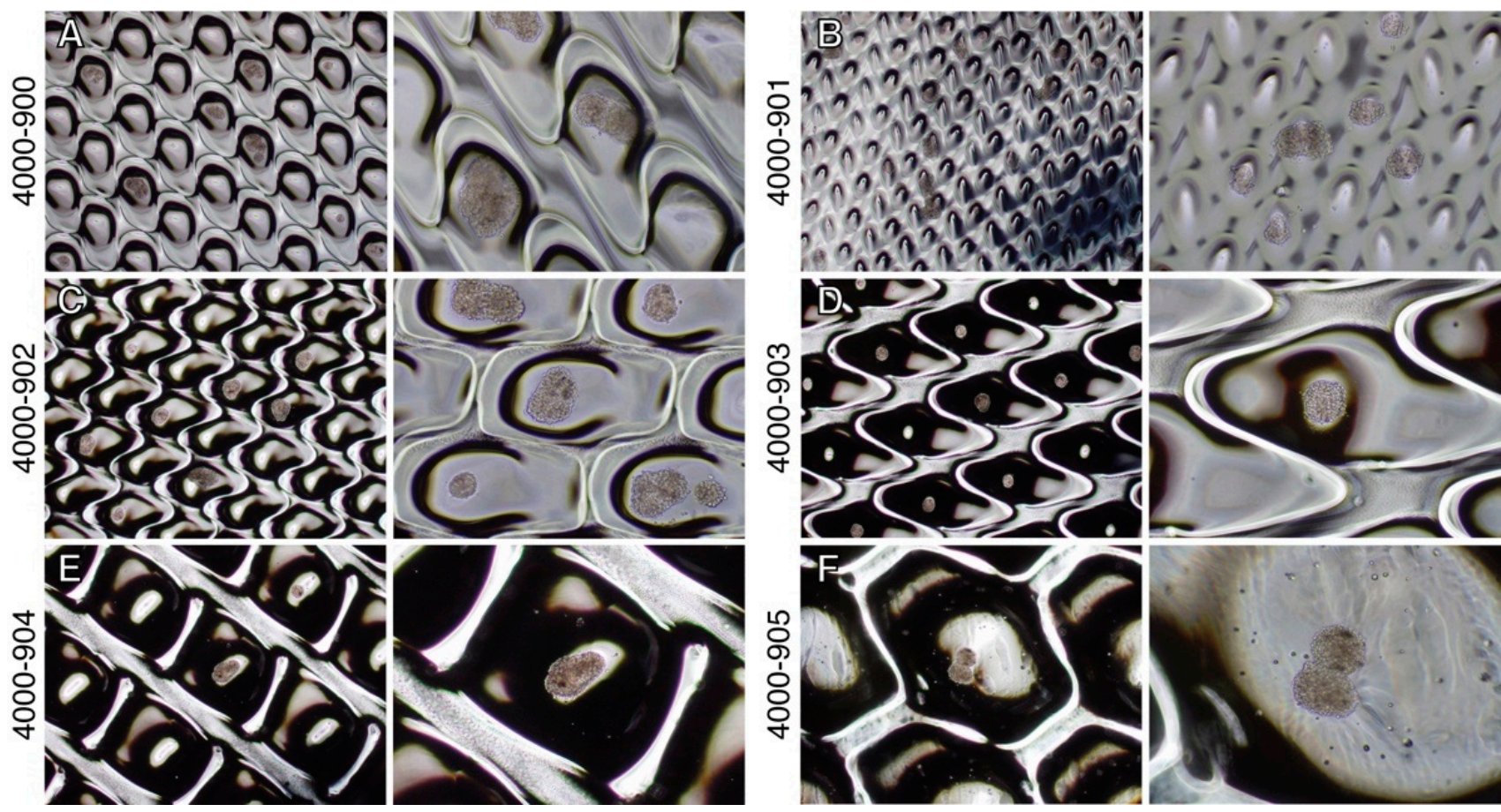

Figure 1. Cells cultured giving rise to spheroid forming units within EZSPHERE ${ }^{\circledR}$ dish (A) type 4000-900, (B) type 4000-901, (C) type 4000-902, (D) type 4000-903, (E) type 4000-904, and (F) type 4000-905 at $4 \times$ (left) and 10× (right) magnification. Images visualized by inverted phase contrast microscope. 20,000 human nucleus pulposus cells were seeded per dish and cultured for 14 days at $5 \% \mathrm{CO}_{2}, 5 \% \mathrm{O}_{2}$, and $37^{\circ} \mathrm{C}$.

NP cells ( $n=1$, donor E32) were also cultured in EZSPHERE ${ }^{\circledR}$ dish type 4000-903 with normal medium or medium supplemented with $100 \mathrm{ng} / \mathrm{mL}$ epidermal growth factor (EGF; R\&D Systems, Minneapolis, MN, USA), 10 ng/mL FGF2 (PeproTech, Cranbury, NJ, USA), $100 \mathrm{ng} / \mathrm{mL}$ platelet-derived growth factor (PDGF; R\&D Systems), or a combination of all three factors. The colonies obtained were similarly harvested and evaluated.

\subsection{Cryopreservation of NP Cells}

After confirming they were free of contamination and the state of the cells, primary NP cells were treated with $5 \mathrm{~mL}$ of TrypLE Express for $3 \mathrm{~min}$ and then collected into a $15 \mathrm{~mL}$ conical tube. Samples were centrifuged at $500 \times g$ for $5 \mathrm{~min}$ at $4{ }^{\circ} \mathrm{C}$, resuspended in $5 \mathrm{~mL}$ of buffered saline, and centrifuged again at $500 \times g$ for $5 \mathrm{~min}$ at $4{ }^{\circ} \mathrm{C}$. The cells were counted using the trypan blue exclusion method to determine their cell number and viability.

For the first experiment, the cell suspension (donor T19) was centrifuged once more to prepare a $1 \mathrm{~mL}$ suspension of CELLBANKER 1 (CB1), STEM-CELLBANKER GMP grade (SCB), or STEM-CELLBANKER DMSO Free GMP grade (SCBD-Free) (all from Zenoaq Resource, Fukushima, Japan) (Table 2), each containing $1 \times 10^{6}$ cells in their respective cryopreservation solution to be dispensed into a cryotube. The samples were kept at room temperature or on ice for $0.5,1,2,3,4$, and $5 \mathrm{~h}$, and cell viability was directly analyzed either or analyzed following cryostorage at $-80^{\circ} \mathrm{C}$ for 1 day. Cryostorage was prepared with 
BICELL containers (Nihon Freezer, Tokyo, Japan) in same way as previously reported [22] to control the cooling rate.

Table 2. Details of cryopreservation solutions. Whether include the animal serum, clears GMP grade, and concentration of DMSO are listed for each cryopreservation. CB-1: CELLBANKER 1, SCB: STEM-CELLBANKER GMP grade, SCBD-free: STEM-CELLBANKER DMSO Free GMP grade, CS10: CryoStor ${ }^{\circledR}$ CS10, and PF: Pro Freeze ${ }^{\mathrm{TM}}-\mathrm{CDM}$.

\begin{tabular}{cccc}
\hline Cryopreservation & Animal Serum & Concetration of DMSO & GMP Grade \\
\hline CB1 & Included & $10 \%$ & Not Cleared \\
SCB & Not Included & $10 \%$ & Cleared \\
SCBD-free & Not Included & $0 \%$ & Cleared \\
CS10 & Not Included & $10 \%$ & Cleared \\
CP-1 $1^{\mathrm{TM}}$ & Not Included & $5 \%$ & Not Cleared \\
PF & Not Included & $15 \%$ & Not Cleared \\
\hline
\end{tabular}

Next, the effects of cryopreservation solutions on NP cell potency and surface marker expression were examined. Based on the previous step, a $3 \mathrm{~h}$ incubation time on ice was selected. NP cells ( $n=3, \mathrm{~T} 19, \mathrm{~A} 24$, and T23) were aliquoted at $1 \times 10^{6}$ cells in $1 \mathrm{~mL}$ of CB1, SCB, or SCBD-Free. The cells were then frozen at $-80^{\circ} \mathrm{C}$ for 1 day, thawed, and cultured in monolayer culture for 5 days. The cells were retrieved using TrypLE Express and analyzed by flow cytometry.

Tie2 expression and cell viability of NP cells ( $n=1$, donor, T19) were examined using six different cryopreservation compositions: CB1, SCB, SCBD-Free, CryoStor ${ }^{\circledR}$ CS10 (CS10) (Stemcell Technologies, Vancouver, BC, Canada), CP-1 ${ }^{\mathrm{TM}}$ (Kyokuto Pharmaceutical Industry, Tokyo, Japan), and Pro Freeze ${ }^{\mathrm{TM}}-\mathrm{CDM}$ (PF) (Lonza Bioscience, Basel, Switzerland). The final tubes were incubated on ice, frozen at $-80^{\circ} \mathrm{C}$, and cultured before being analyzed as previously described.

Finally, $1 \times 10^{6} \mathrm{NP}$ cells $(n=3$, T19, A18, and T18) were kept in $1 \mathrm{~mL}$ of CB1 or CS10 on ice or at room temperature for $0,2,3$, or $5 \mathrm{~h}$. Cells were either analyzed directly or cryopreserved at $-80^{\circ} \mathrm{C}$ for 1 day.

\subsection{Thawing Protocol of NP Cells}

Cells cryopreserved in cryotubes were slowly warmed in a bath with $37^{\circ} \mathrm{C}$ water for about one minute. The tube was removed from the pre-heated water and kept on room temperature until complete thawing was observed. When thawed, the solution was carefully transferred to a falcon tube, and dropwise media containing $10 \%$ FBS was added to slowly resuspend the cells and dilute the cryo-storage media. The samples were then centrifuged at $1200 \mathrm{rpm}$ for $5 \mathrm{~min}$ at $4{ }^{\circ} \mathrm{C}$ to collect the cells and applied for the respective experiments.

\subsection{Colony Formation and Cell Proliferation Rates}

After the cells were cultured for 14 days in EZSPHERE ${ }^{\circledR}$ plates, an inverted phasecontrast microscope was used to count the number of colonies that had formed per 100 wells. To calculate the number of cells, the entire colonies were collected, centrifuged, and treated with $1 \%$ Liberase (Roche) for $30 \mathrm{~min}$ at $37^{\circ} \mathrm{C}$. The cells were centrifuged again and resuspended, and the number of cells derived from the colonies was counted. 


\subsection{Cell Viability}

Cell viability was measured using the standard trypan blue exclusion method and an inverted phase-contrast microscope; the percentages of living and dead cells were counted.

\subsection{Real-Time Polymerase Chain Reaction (PCR) Analysis}

Cultured human NP cells ( $n=3$, E32, A16 m, and K21) were homogenized using ISOGEN II (Nippon Gene, Tokyo, Japan), and RNA was prepared using an RNAqueous Micro RNA isolation kit (Applied Biosystems, Thermo Fisher Scientific, MA, USA) following the manufacturer's instructions. High-Capacity cDNA Reverse Transcription Kits (Applied Biosystems 4387406) were used to reverse transcribe mRNA and to synthesize cDNA. Based on TaqMan gene expression assays (Applied Biosystems), gene expression levels were detected using TaqMan Universal PCR Master Mix and the following primers: TaqMan Gene Expression (human): ACAN (Hs00153936; Applied Biosystems), COL1A2 (Hs01028956; Applied Biosystems), COL2A1 (Hs00264051; Applied Biosystems), and ANGPT1 (Hs00919202; Applied Biosystems). PCR was performed using an amplification machine (7500; RealTime PCR Systems) with stage $1\left(95^{\circ} \mathrm{C}\right.$ for $20 \mathrm{~s} \times 1$ cycle) and stage $2\left(95^{\circ} \mathrm{C}\right.$ for $3 \mathrm{~s}, 60^{\circ} \mathrm{C}$ for $30 \mathrm{~s} \times 50$ cycles). $\mathrm{C}_{\mathrm{T}}$ values were calculated relative to the $\mathrm{C}_{\mathrm{T}}$ value for the housekeeping gene GAPDH (4333764F; Applied Biosystems).

\subsection{Flow Cytometry and Fluorescence-Activated Cell Sorting}

NP cells were analyzed using a FACSCalibur flow cytometer (BD Biosciences, Franklin Lakes, NJ, USA). Only living cells were targeted by using a living (propidium iodidenegative) gate. The cell sorting methods and monoclonal antibodies used for analysis were performed as described previously [13].

\subsection{Statistical Analysis}

All data were collected and processed using Microsoft Excel (Microsoft, Redmond, WA, USA). Statistical analysis was performed using IBM SPSS Statistics software (version 26; IBM Corp., Armonk, NY, USA). Significant differences were identified using the MannWhitney $U$ test and Kruskal-Wallis test. All values are presented as mean ( \pm standard deviation). $p$ values of $<0.05$ were considered to be significant.

\section{Results}

\subsection{Spheroid Colony-Formation and Cell Proliferation Rates in EZSPHERE Dishes}

The ability of EZSPHERE dishes to support NP cell colony formation was evaluated by determining the colony formation and cell proliferation rates (Figure 1). Interestingly, the colonies formed in each plate were similar in size (Figure 1). The average colony formation rates were $9.1 \%( \pm 3.0 \%)$ for type $4000-901,15.6 \%( \pm 9.6 \%)$ for type $4000-900,24.0 \%( \pm 1.0 \%)$ for type $4000-902,45.1 \%( \pm 12.1 \%)$ for type $4000-903,17.5 \%$ ( $\pm 7.0 \%)$ for type $4000-904$, and $15.1 \%( \pm 5.1 \%)$ for type $4000-905$. Dish 4000-903 significantly outperformed almost all other dish types (Figure 2A).

Similarly, the cell proliferation rates were highest using the 400-903 plate, although the only significant difference was compared with 4000-905 ( $p=0.029)$ (Figure 2B). Dish type 4000-903 seemed to be the most suitable type for NP cell CFU culture. Next, growth factor supplementation showed strongly increased proliferation rates by up to 45 times when stimulated with FGF2 or 62.5 times when stimulated with all three factors combined (Figure 2C). 
A

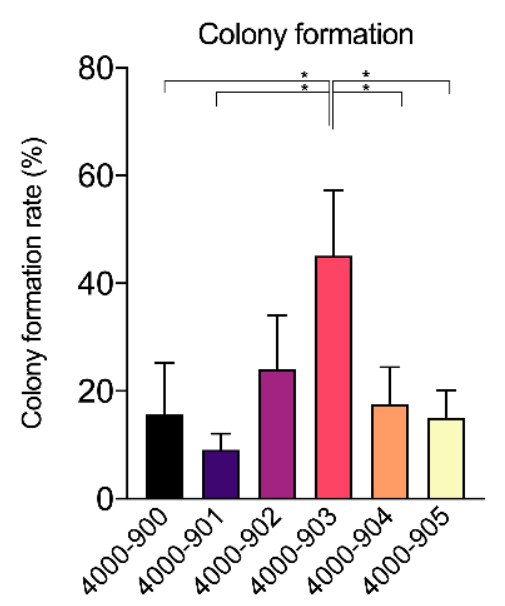

B

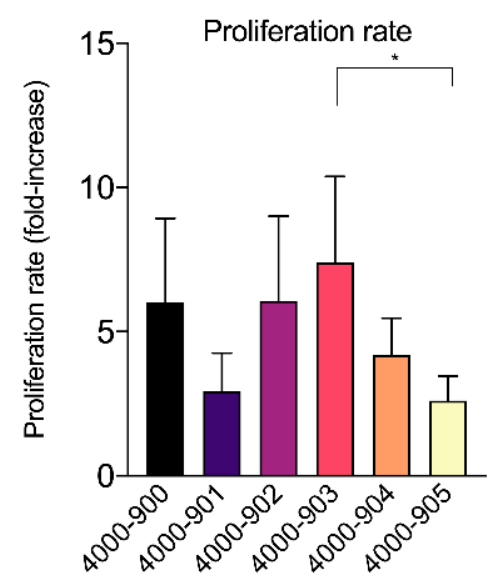

C

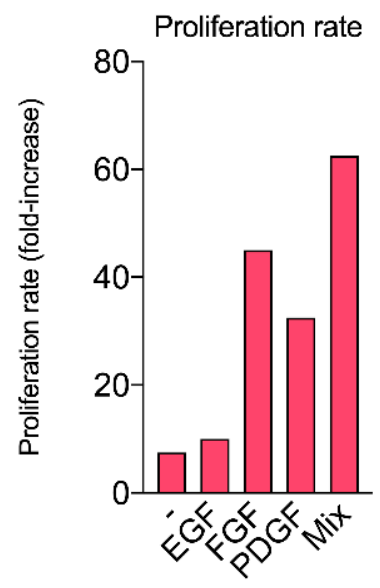

Figure 2. (A) The rate of spheroid colonies that formed and (B) fold increase of cells on different EZSPHERE ${ }^{\circledR}$ dish types derived from 20,000 human nucleus pulposus cells $(n=4)$ following 14 days of culture. (C) The fold-increase in cell numbers following culture of nucleus pulposus cells $(n=1)$ on EZSPHERE ${ }^{\circledR}$ dish type $4000-903$, without $(-)$ or with $100 \mathrm{ng} / \mathrm{mL}$ epidermal growth factor (EGF), $10 \mathrm{ng} / \mathrm{mL}$ fibroblast growth factor (FGF), $100 \mathrm{ng} / \mathrm{mL}$ platelet derived growth factor (PDGF), and a combination of all three growth factors (Mix). Data is presented as mean values with error bars presenting standard deviation. * $p<0.05$,

\subsection{NP Cell Marker Expression in EZSPHERE Spheroid Colonies}

Real-time PCR was performed after culturing cells in each of the six types of EZSPHERE dishes. The expression levels of ANGPT1 and COL2A1 were higher in 3D compared with 2D culture (Figure 3A,D). The COL2A1 expression was particularly prominent, which supports previous reports of high ECM production performance in colony-forming cells [9]. Augmentation of EZSPHERE culture conditions by growth factor supplementation revealed strong reduction in the expression levels of ACAN, COL1A2, COL2A1, and ANGPT1. (Figure 3E-H). Notably, the standard deviation for type 4000-901 was observably high for COL2A1 and ANGPT1 outcomes, predominantly due to high expression found for the A29 donor. (Figure 3A,D) The expression levels for the FGF2- and PDGF-supplemented conditions were similar to those of the monolayer-cultured NP cells.

\subsection{Cell Viability after Addition of Cryopreservation Solution}

To examine the effects of different cryopreservation solutions on NP cells during mass cell batch production, we tested extended exposure of NP cells to three types of cryopreservation solution (CB1, SCB, and SCBD-Free). At room temperature, cells exposed to SCB and SCBD-Free showed a rapid decline in cell viability, with $>50 \%$ cell loss within $1 \mathrm{~h}$ (Figure $4 \mathrm{~A}$ ). In the same process on ice, a high cell viability of $\geq 80 \%$ was obtained in all solutions for up to $2 \mathrm{~h}$, but the number of viable cells decreased with longer incubations in SCB and SCBD-Free (Figure 4C). Samples left at room temperature for $\geq 1 \mathrm{~h}$ followed by cryopreservation showed complete loss of viability (Figure 4B). Samples kept on ice before cryopreservation had better viability, although cell viability was $67 \%$ in SCB and $57.8 \%$ in SCBD-Free conditions after $2 \mathrm{~h}$ and decreased further with time (Figure 4D). Cells exposed to CB1 had a survival rate of $\geq 90 \%$ even after being left for $5 \mathrm{~h}$ on ice, although the cell viability decreased with time at room temperature. 
A

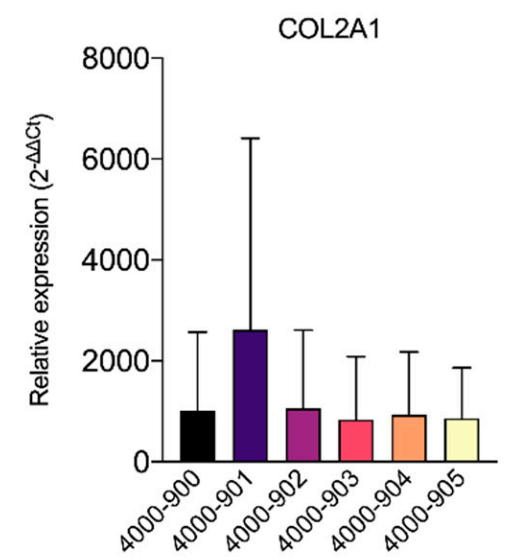

C

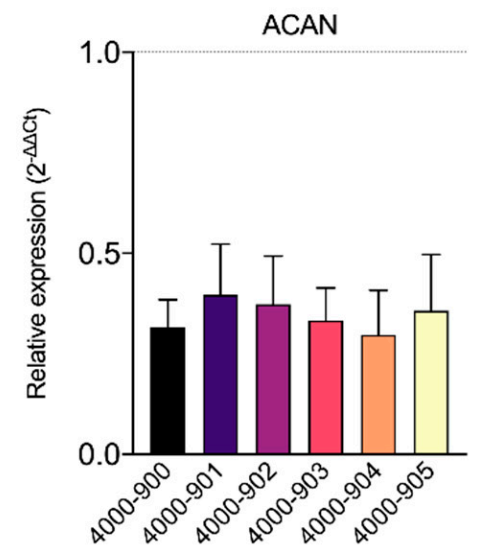

E

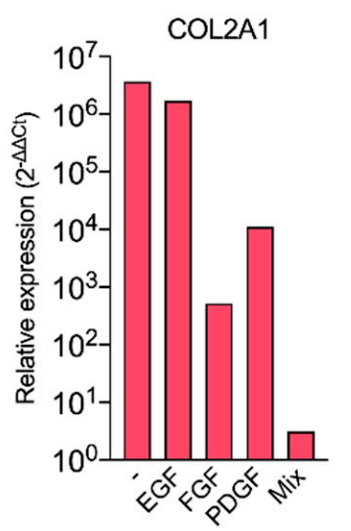

$F$

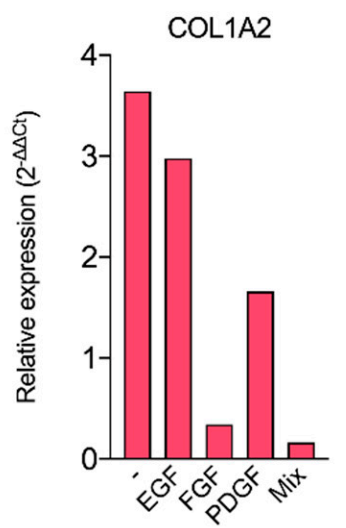

B

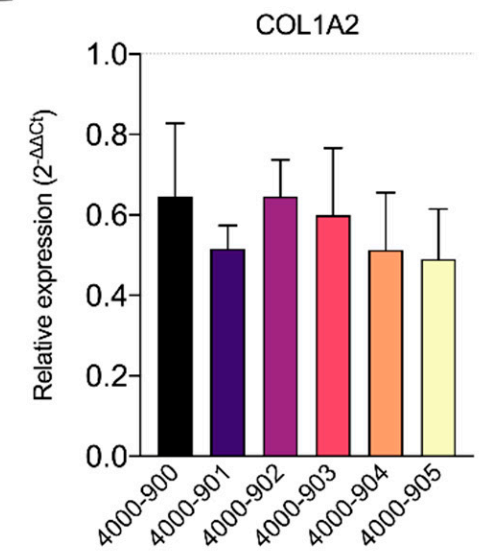

D

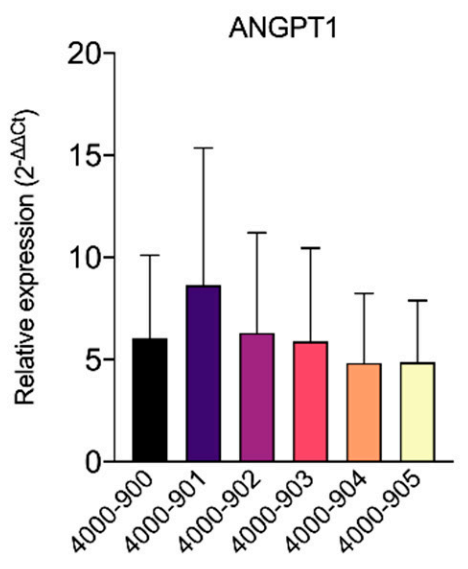

G

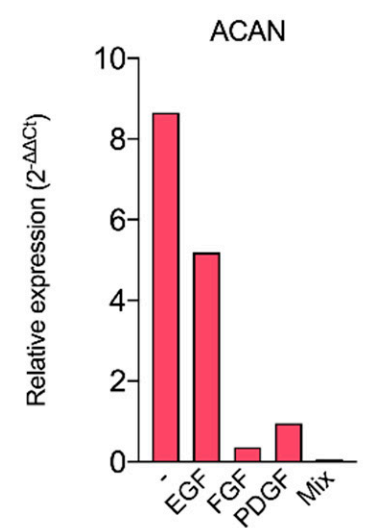

$\mathrm{H}$

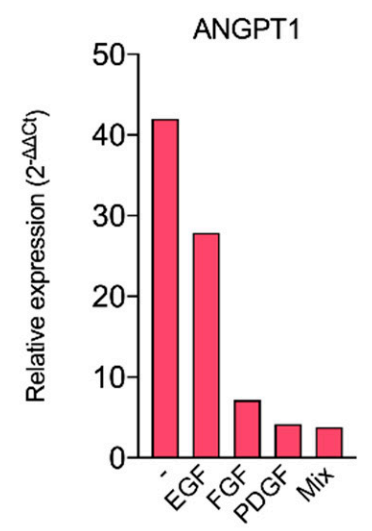

Figure 3. Relative gene expression levels of (A) COL2A1, (B) COL1A2, (C) ACAN, and (D) ANGPT1 for nucleus pulposus cell spheroid colonies cultured on different EZSPHERE ${ }^{\circledR}$ dish types. $(n=4)$ Relative gene expression of $(\mathrm{E})$ COL2A1, (F) COL1A2, (G) ACAN, and (H) ANGPT1 of nucleus pulposus cell cultured on EZSPHERE ${ }^{\circledR}$ dish 4000-903 $(n=1)$ without (-) or with $100 \mathrm{ng} / \mathrm{mL}$ epidermal growth factor (EGF), $10 \mathrm{ng} / \mathrm{mL}$ fibroblast growth factor (FGF), $100 \mathrm{ng} / \mathrm{mL}$ platelet derived growth factor (PDGF), or a combination of all three growth factors (Mix). Data is calculated relative to monolayer cultured nucleus pulposus cells. Values derived using $2^{-\Delta \Delta \mathrm{Ct}}$ method and presented as mean values with error bars presenting standard deviation. 
A

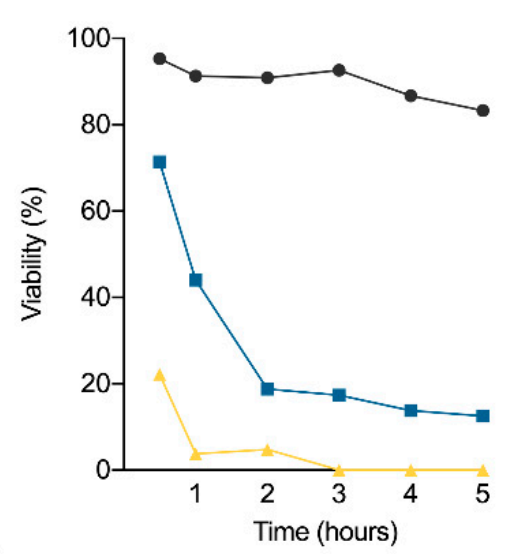

C

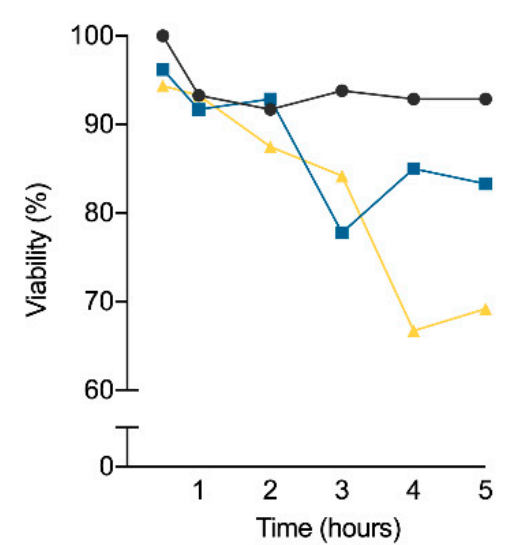

B

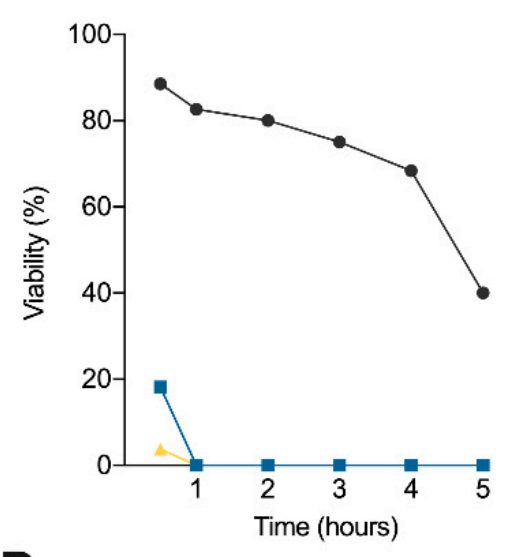

$\rightarrow$ CB-1

STEM-CB

STEM-CB DMSO FREE
D

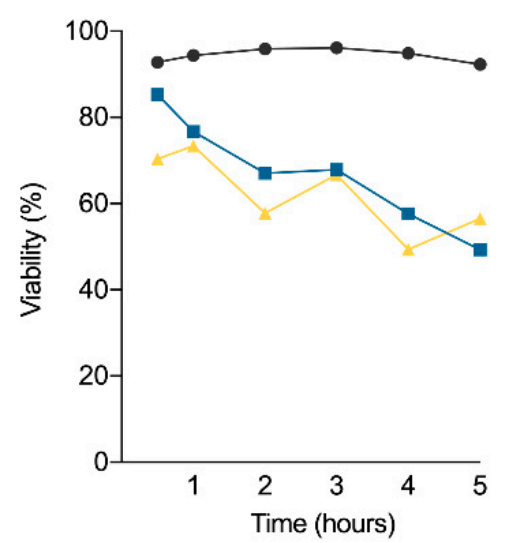

Figure 4. Cells $(n=1)$ were suspended in CellBanker-1 (CB-1), STEM-CELLBANKER (STEM-CB), or STEM-CELLBANKER

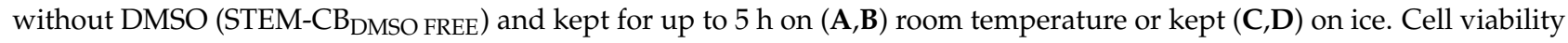
tested at multiple time points either before or after 1 day of cryopreservation.

\subsection{Cell Potential after Cryopreservation}

Next, NP cells were exposed to cryostorage solutions (CB1, SCB, or SCBD-Free) for $3 \mathrm{~h}$ on ice before freezing. The cells were thawed and subsequently cultured. The cells frozen in CB1 had an average cell viability of $95.7 \%$ (Figure $4 \mathrm{~A}$ ), but the other two cryopreservation solutions resulted in considerable cell loss (Figure 5A). The average growth rate of cells frozen in CB1 was 5.9 times $(p=0.53)$, which was lower than the growth rate of cells frozen in SCB (8.93 times; Figure 5B). The Tie2- and CD24-positive rates in flow cytometry analysis showed a trend toward reduced Tie2- and CD24-expressing fractions for NP cells kept in CB 1 compared with SCBD-Free, although this difference was not significant (Figure 5C,D).

Additional investigation with a wider range of cryopreservation solutions (CB1, SCB, SCBD-Free, CS10, CP-1, and PF) revealed viability ranging from $63.6 \%$ (PC) to $84.6 \%$ (CS10) (Figure 6A). Interestingly, the Tie2-positivity rates of NP cells was $12.6 \%$ in cells in CS10, suggesting a higher Tie2 retention rate in cells in CS10 than in CB1 (Figure 6B). 
A
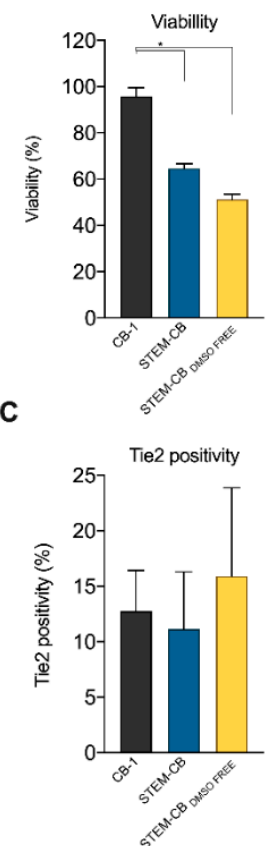

B
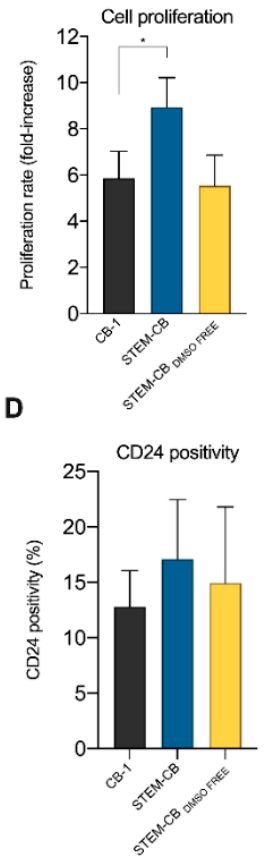

Figure 5. Cells $(n=3)$ were suspended in CellBanker-1 (CB-1), STEM-CELLBANKER (STEM-CB), or

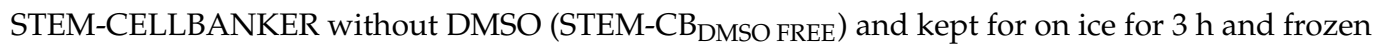
for 1 day. Subsequently (A) cell viability was assessed. Following cryostorage and thawing cells were seeded cultured for 5 days. The (B) fold-increase in cell numbers was analyzed, as well as the fraction of (C) Tie2 expressing and (D) CD24 expressing cells as analyzed by flow cytometry. Data is presented as mean values with error bars presenting standard deviation. ${ }^{*} p<0.05$.

A

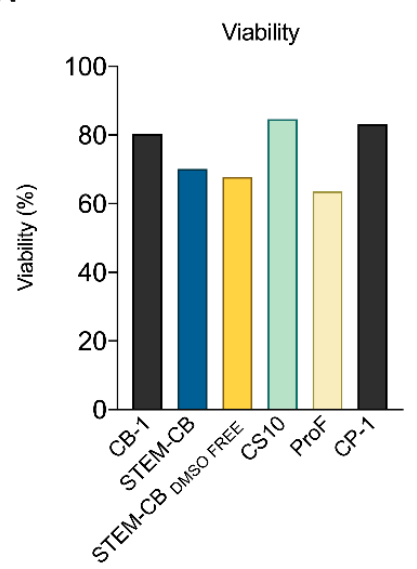

B

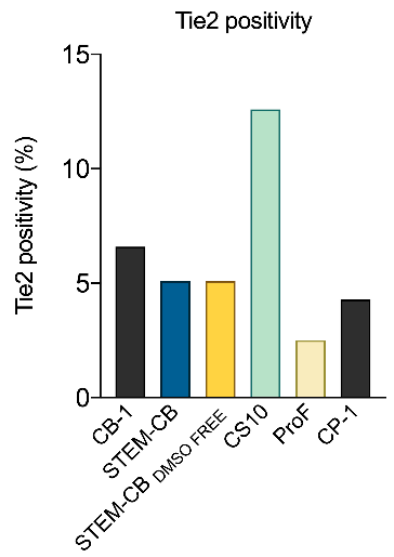

Figure 6. Comparison of 6 types of cryopreservation solutions, namely CELLBANKER 1 (CB1), STEM-CELLBANKER GMP grade (STEM-CB), STEM-CELLBANKER DMSO Free GMP grade

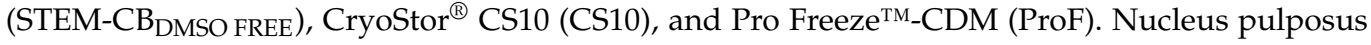
cells suspended in the cryopreservation solutions and kept on ice for $3 \mathrm{~h}$ before cryostoring them for 1 day. The cells were recovered and cultured for 5 days. Subsequently, the (A) viability rate and the (B) fraction of Tie2 positive cells were determined. Data is presented as mean values with error bars presenting standard deviation.

Finally, CS10 and CB1 were used to resuspended primary NP cells and the effects on cell viability in cells with time left at room temperature or on ice were examined. The average cell viability was $95.2 \%( \pm 1.8 \%)$ for cells in CS10, and this value was maintained even after $5 \mathrm{~h}$ on ice (Figure $7 \mathrm{~A})$ and at $89.9 \%(6.5 \%)$ in cells stored at room temperature 
(Figure 7B). CB1 produced similar results (Figure 6B). The average cell viability after cryopreservation and thawing also remained high: $88.4 \%( \pm 4.6 \%)$ in cells on ice in CS10 or $87.7 \%( \pm 6.0 \%)$ in CB1 (Figure 7C). However, when kept at room temperature, the survival rate after cryopreservation and thawing appeared to decrease to $67.5 \%( \pm 29.9 \%)$ after $3 \mathrm{~h}$ in CS10 compared with $82.1 \%( \pm 6.5 \%)$ in CB1 (Figure 7D).

A

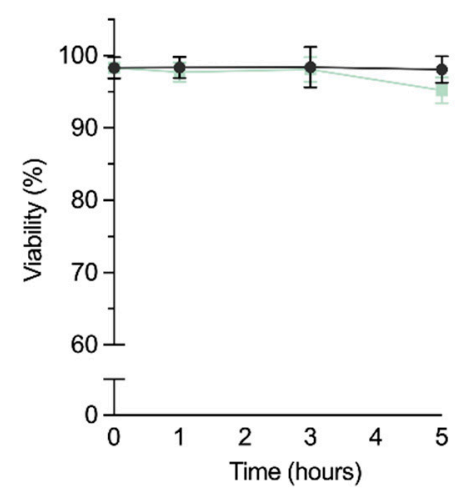

C

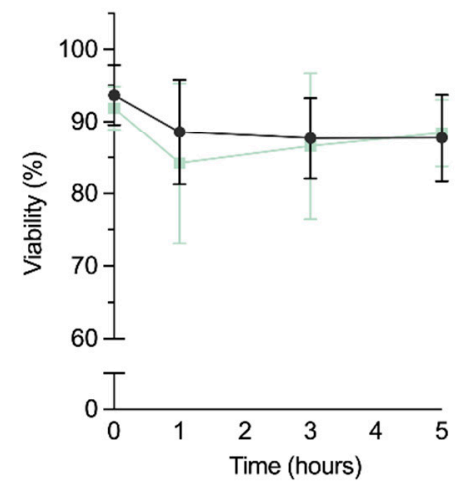

B

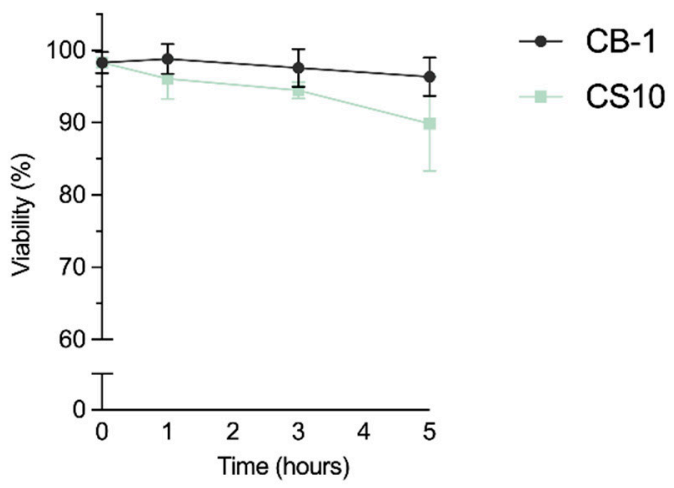

D

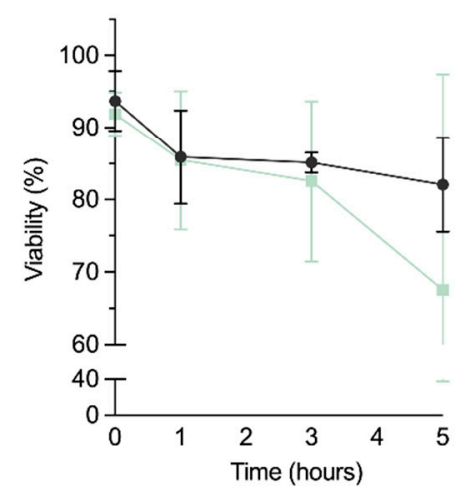

Figure 7. Cells $(n=3)$ were suspended in CellBanker-1 (CB-1) and CryoStor-10 (CS10) and kept for up to $5 \mathrm{~h}$ on (B,D) room temperature or $(\mathbf{A}, \mathbf{C})$ on ice. Cell viability tested at multiple time points either before or after 1 day of cryopreservation.

\section{Discussion}

In this study, we aimed to tackle some practical issues that potentially limit the market and clinical translation of NP progenitor cells as a regenerative cell transplantation product. First, we examined the ability of EZSPHERE cultures plates to allow large-scale colonyforming culture of NP progenitor cells. Second, we examined the effects of cryopreservation solution on NP cell viability and potency under real-world conditions.

Spheroid formation rates were highest using EZSPHERE plate type 4000-903, which has wells with a diameter of $800 \mu \mathrm{m}$ and a depth of $400 \mu \mathrm{m}$. The proliferation rates were also the highest for this plate type. 3D cell cultures are used widely in research in various tissues, such as the vascular endothelium and cartilage, in an attempt to simulate the in vivo microenvironment. Better differentiation potential has been demonstrated in vitro compared with monolayer cultures of MSCs in spheroid cultures [26]. Previous work has shown that spheroid-forming NP cells have a greater ability to produce ECM $[9,27]$ and are thus considered as promising cell types for regenerative and cellular therapeutics.

Our data support these previous findings, as EZSPHERE cultured cells exhibited a markedly higher COL2A1 expression (on average 836-fold) compared with monolayer cultured NP cells. By contrast, COL1A2 expression, as a negative NP marker [28], was markedly downregulated (on average 0.6 -fold). The ECM produced by NP cells in human IVD tissue is classified mainly as type II collagen and proteoglycans, and IVD is not formed normally in type II collagen-deficient mice [29]. Therefore, type II collagen is 
thought to play an important role in the formation of the IVD, which suggests that NP cells that can be collected by this culture method should have excellent functionality. This supports our previously stated belief that the ability for colonization is an indicator of NP functionality [7].

We were particularly interested in the potential application of EZSPHERE plates as an alternative to the current standard of methylcellulose-based CFU-s cultures [13]. Culturing in EZSPHERE plates has an additional potential advantage because the diffusion gradient of the cultured cells and solution can be controlled more closely, which should improve the reproducibility and quality control for commercialization [30]. Conversely, methylcellulose-based culture leads to the formation of spheroid colonies of different sizes and, because of the high viscosity of the culture medium, cell recovery can be complicated. By contrast, the size of colonies obtained using EZSPHERE culture relies on the well's dimension, which produces relatively uniform colony sizes (Figure 1A). Moreover, the colonies are not maintained in a hydrogel, and the recovery of large quantities of colonies is much easier.

The EZSPHERE culture systems offer a promising culture device that could be scalable for production of CFU-s NP cells. As a goal for commercialization, for example, cells from one sample must be extracted and available for at least 100 people. This is important because IVD cell therapy products generally involve the transplantation of a total of 1-100 $\times 10^{6}$ cells per disc (although an optimal concentration has not been determined) (15). For example, in our previous clinical trial [16], we obtained an average of $1.24 \times 10^{6}$ primary cells $/ 7.92 \mathrm{~g}$ tissue per patient donor material (Table 3). Assuming that a cell therapy product requires $1 \times 10^{6} \mathrm{NP}$ cells, $\sim 100$ times the cell proliferation effect is required. However, with the EZSPHERE method alone, the cell proliferation rate was 7.75-fold in our study, which would mean that only nine patients on average could be treated with cells from a single-batch production following EZSPHERE culture methods. Our data in the present study show that growth factor supplementation can markedly increase the NP cell proliferation rate. These findings are consistent with previous work showing that FGF2 has a Tie2 expression-enhancing effect on NP cells [14]. In our study, FGF2 supplementation had positive effect by increasing the cell proliferation rate by up to $62.5 \%$. This would make it possible to manufacture NP cell products for about 77 patients from a single tissue sample. However, cells cultured with other growth factors showed a marked decrease expression of COL2A1 and ACAN, which may be a disadvantage compared with the original colony assay culture. Further analysis and in vivo experimentation are needed to elucidate these effects.

Table 3. Details of previous Mochida et al. clinical trial of autologous NP cell transplantation. In the clinical trial of Mochida et al. [16], surgically removed NP tissue and obtained cells were cultured and administered to prevent adjacent degenerative disc disease. The average time required to recover the transplanted cells was $122.9 \mathrm{~min}$ using a similar procedure in this study. IVD: intervertebral disc, NPC: nucleus pulposus cell.

\begin{tabular}{ccccccc}
\hline & Age & Sex & $\begin{array}{c}\text { IVD Tissue Amount } \\
\text { (g) }\end{array}$ & $\begin{array}{c}\text { Number of Collectied } \\
\text { NPC }\end{array}$ & $\begin{array}{c}\text { Number of Cultured } \\
\text { NPC }\end{array}$ & $\begin{array}{c}\text { Cultured Cell } \\
\text { Recovery Time (min) }\end{array}$ \\
\hline 1 & 21 & M & 8.2 & $1.25 \times 10^{6}$ & $7.2 \times 10^{6}$ & 115 \\
2 & 28 & M & 4 & $0.93 \times 10^{6}$ & $5.85 \times 10^{6}$ & 113 \\
3 & 28 & M & 10.9 & $3.42 \times 10^{6}$ & $10.80 \times 10^{6}$ & 105 \\
4 & 27 & M & 8.9 & $1.20 \times 10^{6}$ & $5.8 \times 10^{6}$ & 174 \\
5 & 29 & M & 3.6 & $0.71 \times 10^{6}$ & $3.36 \times 10^{6}$ & 100 \\
6 & 28 & M & 7.7 & $1.0 \times 10^{6}$ & $3.02 \times 10^{6}$ & 120 \\
7 & 21 & M & 11.9 & $1.05 \times 10^{6}$ & $2.88 \times 10^{6}$ & 120 \\
8 & 29 & M & 6.6 & $0.5 \times 10^{6}$ & $2.48 \times 10^{6}$ & 125 \\
9 & 21 & F & 9.1 & $0.93 \times 10^{6}$ & $2.63 \times 10^{6}$ & 115 \\
10 & 25 & M & 8.3 & $1.43 \times 10^{6}$ & $2.80 \times 10^{6}$ & 142 \\
\hline
\end{tabular}


The different types of cryopreservation solutions and exposure times used in the cryopreservation of cellular products are thought to affect the product quality [24]. Especially in undifferentiated cells such as MSCs, the maintenance and prevention of phenotype loss and changes in metabolism during storage are important. Reports have suggested inadequate therapeutic results can arise because of the effects of cryopreservation in clinical trials using MSCs [31,32]. Given our aim to deliver multipotent, undifferentiated NP progenitor cells with high Tie2 positivity, concerns were raised about the effects of cryopreservation on NP cells and their potency. In the trial reported by Mochida et al. [16], the collection of cultured cells before their administration in the operating room was performed in a similar fashion as in our experiments; that is, the NP cells were cryopreserved before transplantation.

The purpose of the current study was to identify the most appropriate cryopreservation solutions and freezing procedures by investigating their effects on NP cells over time. Of the 10 patients treated in the previous clinical trial [16], an average of $4.6 \times 10^{6} \mathrm{NP}$ cells were administered following harvest from their respective coculture conditions. At the time of surgery, the cryostored NP cells were recovered, thawed, and transported from a cell-processing center to the operating room, and the waiting time before transplantation was on average $122.9 \mathrm{~min}$, which meant that the cells were exposed to the cryopreserving agents for about $2 \mathrm{~h}$. Our current results show that NP cells subjected to cryopreserving agents for up to $3 \mathrm{~h}$ had survival rates of $\leq 70 \%$ in SCB and SCBD-Free. Interestingly, cells kept on ice in CB1 retained a cell viability of $90 \%$ for up to $5 \mathrm{~h}$.

Although CB1 has been shown to be optimal, for clinical translation, it is desirable to preserve and administer cells in solutions devoid of animal-derived serum or DMSO. Therefore, we examined six additional commercial cryopreserving preparations. We found that cell viability after thawing was maintained at $\geq 80 \%$ with CB1, CS10, and CP-1. CS10 was also able to maintain a high Tie2-expressing faction. In addition, CS10 is an animal component-free GMP-certified formula, making it potentially ssafer to administer directly to patients than CB1 when used as an OTS [23]. However, SCB is a product with an identical composition as $\mathrm{CB} 1$, but without animal components, and this resulted in a sharp decrease in viability at room temperature or on ice with time. Moreover, the CS10 formula does contain $10 \%$ DMSO, which showed a decrease in the number of cells after an incubation of $\geq 3 \mathrm{~h}$ incubation, which suggests that the collection and freezing of harvested cells should be performed in the shortest possible time. If we select one type of cell preservation solution for industrialization, CS10 is considered to be most optimal because it showed similar levels of cell viability maintenance as CB1 but does not contain any animal components.

The limitation of our study is that procurement of human-derived cell sources was limited, and some experiments had a limited sample size. Moreover, in this experiment, the cryopreservation period was only $24 \mathrm{~h}$ and long-term storage might have a more impactful effect on NP cells. Still, freezing and thawing process is likely the most important and damaging phase in cryopreservation, as such we believe this experiment is sufficient to compare the usefulness of solutions. Additionally, we did not further assess the impact of cryopreservatives on NP cell potency. Furthermore, a recent study by Croft et al. suggested that the type of cryopreservation medium, including CS10, had limited effects on NP cell multipotency [33]. The work by Hiraishi et al. suggested no effect on the in vivo regenerative potency of NP cells [24]. However, the effects on the potentially more sensitive Tie2 cells remains unclear [13]. Further advances in culture, storage, and logistics for NP cell-based cell therapeutics are needed to expand their potential as effective and marketable products in the clinic $[17,25]$.

\section{Conclusions}

EZSPHERE culture plates enabled us to examine colony formation in cell culture without the use of methylcellulose or other hydrogel products. EZSPHERE culture methods produced high colony formation and increased proliferation rates, which could be augmented by FGF supplementation. Continued examination of the optimal culture methods is required for further development and commercialization. The derived cells should be 
assessed in vivo for their potential as a regenerative medicinal product. Our study showed that CS10 is presently, the best cryopreservation medium for retaining NP progenitor cell phenotype and viability when cells are kept on ice or even at room temperature for up to $3 \mathrm{~h}$. Our findings provide information that may be useful for the translation of NP cell-based therapeutics to the clinic.

Author Contributions: Conceptualization, Y.N., D.S. and K.S.; methodology, K.S.; formal analysis, K.S., E.M., J.S. and T.W.; investigation, D.S.; resources, N.H., E.M. and T.W.; data curation, Y.N. and E.M.; writing—original draft preparation, K.S.; writing—review and editing, D.S., K.S., T.W., N.H., M.S., M.W. and J.S.; visualization, J.S.; supervision, M.S.; project administration, M.S. and M.W.; funding acquisition, D.S., M.S. and M.W. All authors have read and agreed to the published version of the manuscript.

Funding: This research received no external funding.

Institutional Review Board Statement: The study was conducted according to the guidelines of the Declaration of Helsinki, and approved by the Institutional Review Board for Clinical Research, Tokai University School of Medicine (protocol code 16R-051: 15 July 2016).

Informed Consent Statement: Informed consent was obtained from all subjects involved in the study.

Data Availability Statement: Data can be requested to the corresponding authors upon reasonable request.

Conflicts of Interest: The authors declare no conflict of interest.

\section{References}

1. Strine, T.W.; Hootman, J.M. US national prevalence and correlates of low back and neck pain among adults. Arthritis Rheum. 2007, 57, 656-665. [CrossRef]

2. Vos, T.; Allen, C.; Arora, M.; Barber, R.M.; Bhutta, Z.A.; Brown, A.; Carter, A.; Casey, D.C.; Charlson, F.J.; Chen, A.Z.; et al. Global, regional, and national incidence, prevalence, and years lived with disability for 310 diseases and injuries, 1990-2015: A systematic analysis for the Global Burden of Disease Study 2015. Lancet 2016, 388, 1545-1602. [CrossRef]

3. Oichi, T.; Taniguchi, Y.; Oshima, Y.; Tanaka, S.; Saito, T. Pathomechanism of intervertebral disc degeneration. JOR Spine 2020, 3, e1076. [CrossRef]

4. Frost, B.A.; Camarero-Espinosa, S.; Foster, E.J. Materials for the Spine: Anatomy, Problems, and Solutions. Materials 2019, 12, 253. [CrossRef]

5. O'Halloran, D.M.; Pandit, A.S. Tissue-engineering approach to regenerating the intervertebral disc. Tissue Eng. 2007, 13, 1927-1954. [CrossRef]

6. Antoniou, J.; Steffen, T.; Nelson, F.; Winterbottom, N.; Hollander, A.P.; Poole, R.A.; Aebi, M.; Alini, M. The human lumbar intervertebral disc: Evidence for changes in the biosynthesis and denaturation of the extracellular matrix with growth, maturation, ageing, and degeneration. J. Clin. Investig. 1996, 98, 996-1003. [CrossRef]

7. Weiler, C.; Nerlich, A.G.; Zipperer, J.; Bachmeier, B.E.; Boos, N. 2002 SSE Award Competition in Basic Science: Expression of major matrix metalloproteinases is associated with intervertebral disc degradation and resorption. Eur. Spine J. 2002, 11, 308-320. [CrossRef]

8. Le Maitre, C.L.; Freemont, A.J.; Hoyland, J.A. Localization of degradative enzymes and their inhibitors in the degenerate human intervertebral disc. J. Pathol. 2004, 204, 47-54. [CrossRef] [PubMed]

9. Sakai, D.; Nakamura, Y.; Nakai, T.; Mishima, T.; Kato, S.; Grad, S.; Alini, M.; Risbud, M.V.; Chan, D.; Cheah, K.S.; et al. Exhaustion of nucleus pulposus progenitor cells with ageing and degeneration of the intervertebral disc. Nat. Commun. 2012, 3, 1264. [CrossRef] [PubMed]

10. Guerrero, J.; Häckel, S.; Croft, A.S.; Albers, C.E.; Gantenbein, B. The effects of 3D culture on the expansion and maintenance of nucleus pulposus progenitor cell multipotency. JOR Spine 2020, 4, e1131.

11. Ishii, T.; Sakai, D.; Schol, J.; Nakai, T.; Suyama, K.; Watanabe, M. Sciatic nerve regeneration by transplantation of in vitro differentiated nucleus pulposus progenitor cells. Regen. Med. 2017, 12, 365-376. [CrossRef]

12. Li, X.C.; Tang, Y.; Wu, J.H.; Yang, P.S.; Wang, D.L.; Ruan, D.K. Characteristics and potentials of stem cells derived from human degenerated nucleus pulposus: Potential for regeneration of the intervertebral disc. BMC Musculoskelet. Disord. 2017, 18, 242. [CrossRef] [PubMed]

13. Sakai, D.; Schol, J.; Bach, F.C.; Tekari, A.; Sagawa, N.; Nakamura, Y.; Chan, S.C.W.; Nakai, T.; Creemers, L.B.; Frauchiger, D.A.; et al. Successful fishing for nucleus pulposus progenitor cells of the intervertebral disc across species. JOR Spine 2018, 1, e1018. [CrossRef] [PubMed]

14. Tekari, A.; Chan, S.C.W.; Sakai, D.; Grad, S.; Gantenbein, B. Angiopoietin-1 receptor Tie2 distinguishes multipotent differentiation capability in bovine coccygeal nucleus pulposus cells. Stem Cell Res. Ther. 2016, 7, 75. [CrossRef] 
15. Schol, J.; Sakai, D. Cell therapy for intervertebral disc herniation and degenerative disc disease: Clinical trials. Int. Orthop. 2019, 43, 1011-1025. [CrossRef] [PubMed]

16. Mochida, J.; Sakai, D.; Nakamura, Y.; Watanabe, T.; Yamamoto, Y.; Kato, S. Intervertebral disc repair with activated nucleus pulposus cell transplantation: A three-year, prospective clinical study of its safety. Eur. Cell Mater. 2015, 29, 202-212, discussion 212. [CrossRef]

17. Sakai, D.; Schol, J. Cell therapy for intervertebral disc repair: Clinical perspective. J. Orthop. Translat. 2017, 9, 8-18. [CrossRef]

18. Gruber, H.E.; Ingram, J.A.; Norton, H.J.; Hanley, E.N., Jr. Senescence in cells of the aging and degenerating intervertebral disc: Immunolocalization of senescence-associated beta-galactosidase in human and sand rat discs. Spine 2007, 32, 321-327. [CrossRef]

19. Jiang, L.; Zhang, X.; Zheng, X.; Ru, A.; Ni, X.; Wu, Y.; Tian, N.; Huang, Y.; Xue, E.; Wang, X.; et al. Apoptosis, senescence, and autophagy in rat nucleus pulposus cells: Implications for diabetic intervertebral disc degeneration. J. Orthop. Res. 2013, 31, 692-702. [CrossRef]

20. Zhang, X.; Guerrero, J.; Croft, A.S.; Albers, C.E.; Häckel, S.; Gantenbein, B. Spheroid-Like Cultures for Expanding Angiopoietin Receptor-1 (aka. Tie2) Positive Cells from the Human Intervertebral Disc. Int. J. Mol. Sci. 2020, 21, 9423. [CrossRef]

21. Frauchiger, D.A.; Tekari, A.; May, R.D.; Dzafo, E.; Chan, S.C.W.; Stoyanov, J.; Bertolo, A.; Zhang, X.; Guerrero, J.; Sakai, D.; et al. Fluorescence-Activated Cell Sorting Is More Potent to Fish Intervertebral Disk Progenitor Cells Than Magnetic and Beads-Based Methods. Tissue Eng. Part C Methods 2019, 25, 571-580. [CrossRef]

22. Tanaka, M.; Sakai, D.; Hiyama, A.; Arai, F.; Nakajima, D.; Nukaga, T.; Nakai, T.; Mochida, J. Effect of cryopreservation on canine and human activated nucleus pulposus cells: A feasibility study for cell therapy of the intervertebral disc. Biores. Open Access 2013, 2, 273-282. [CrossRef]

23. Hiraishi, S.; Schol, J.; Sakai, D.; Nukaga, T.; Erickson, I.; Silverman, L.; Foley, K.; Watanabe, M. Discogenic cell transplantation directly from a cryopreserved state in an induced intervertebral disc degeneration canine model. JOR Spine 2018, 1, e1013. [CrossRef]

24. Morris, T.J.; Picken, A.; Sharp, D.M.C.; Slater, N.K.H.; Hewitt, C.J.; Coopman, K. The effect of Me(2)SO overexposure during cryopreservation on HOS TE85 and hMSC viability, growth and quality. Cryobiology 2016, 73, 367-375. [CrossRef]

25. Smith, L.J.; Silverman, L.; Sakai, D.; Le Maitre, C.L.; Mauck, R.L.; Malhotra, N.R.; Lotz, J.C.; Buckley, C.T. Advancing cell therapies for intervertebral disc regeneration from the lab to the clinic: Recommendations of the ORS spine section. JOR Spine 2018, 1, e1036. [CrossRef] [PubMed]

26. Yamaguchi, Y.; Ohno, J.; Sato, A.; Kido, H.; Fukushima, T. Mesenchymal stem cell spheroids exhibit enhanced in-vitro and in-vivo osteoregenerative potential. BMC Biotechnol. 2014, 14, 105. [CrossRef]

27. Lee, J.Y.; Hall, R.; Pelinkovic, D.; Cassinelli, E.; Usas, A.; Gilbertson, L.; Huard, J.; Kang, J. New use of a three-dimensional pellet culture system for human intervertebral disc cells: Initial characterization and potential use for tissue engineering. Spine 2001, 26, 2316-2322.

28. Risbud, M.V.; Schoepflin, Z.R.; Mwale, F.; Kandel, R.A.; Grad, S.; Iatridis, J.C.; Sakai, D.; Hoyland, J.A. Defining the phenotype of young healthy nucleus pulposus cells: Recommendations of the Spine Research Interest Group at the 2014 annual ORS meeting. J. Orthop. Res. 2015, 33, 283-293. [CrossRef] [PubMed]

29. Aszodi, A.; Chan, D.; Hunziker, E.; Bateman, J.F.; Fassler, R. Collagen II is essential for the removal of the notochord and the formation of intervertebral discs. J. Cell Biol. 1998, 143, 1399-1412. [CrossRef] [PubMed]

30. Silverman, L.I.; Flanagan, F.; Rodriguez-Granrose, D.; Simpson, K.; Saxon, L.H.; Foley, K.T. Identifying and Managing Sources of Variability in Cell Therapy Manufacturing and Clinical Trials. Regen. Eng. Transl. Med. 2019, 5, 354-361. [CrossRef]

31. Francois, M.; Copland, I.B.; Yuan, S.; Romieu-Mourez, R.; Waller, E.K.; Galipeau, J. Cryopreserved mesenchymal stromal cells display impaired immunosuppressive properties as a result of heat-shock response and impaired interferon-gamma licensing. Cytotherapy 2012, 14, 147-152. [CrossRef] [PubMed]

32. Moll, G.; Alm, J.J.; Davies, L.C.; von Bahr, L.; Heldring, N.; Stenbeck-Funke, L.; Hamad, O.A.; Hinsch, R.; Ignatowicz, L.; Locke, M.; et al. Do cryopreserved mesenchymal stromal cells display impaired immunomodulatory and therapeutic properties? Stem Cells 2014, 32, 2430-2442. [CrossRef] [PubMed]

33. Croft, A.S.; Guerrero, J.; Oswald, K.A.C.; Häckel, S.; Albers, C.E.; Gantenbein, B. Effect of different cryopreservation media on human nucleus pulposus cells' viability and trilineage potential. JOR Spine 2021, 4, e1140. [CrossRef] [PubMed] 